\title{
Mechanisms of methotrexate resistance in osteosarcoma cell lines and strategies for overcoming this resistance
}

\author{
JIANJUN WANG ${ }^{1}$ and GUOJUN LI ${ }^{2}$ \\ Departments of ${ }^{1}$ Oncology and ${ }^{2}$ Orthopedics, Henan University Huaihe Hospital, Kaifeng, Henan 475001, P.R. China
}

Received February 14, 2014; Accepted September 26, 2014

DOI: $10.3892 / \mathrm{ol} .2014 .2773$

\begin{abstract}
The aim of the present study was to investigate the underlying mechanisms of methotrexate (MTX) resistance in the human osteosarcoma cell line, Saos-2/MTX4.4, and to evaluate various methods of overcoming the resistance to this chemotherapeutic agent. MMT assays were performed to determine the resistance of the primary (Saos-2) and resistant (Saos-2/MTX4.4) cell lines to MTX, cisplatin [cis-diamminedichloroplatinum II (DDP)], ifosfamide (IFO), Adriamycin (ADM), epirubicin (EPI) and theprubicin (THP). The Saos-2/MTX4.4 cells exhibited a low resistance to IFO, ADM, EPI and THP; however, no resistance to DDP was identified. Overall, the Saos-2/MTX4.4 cells exhibited a greater resistance to all the chemotherapeutic agents investigated compared with the Saos- 2 cells. Rhodamine 123 (R123) fluorescence was measured in the Saos-2/MTX4.4 and Saos-2 cells 30 and $60 \mathrm{~min}$ after the addition of R123, and R123 plus verapamil (VER). VER administration increased the intracellular accumulation of R123. In addition, reverse transcription-quantitative polymerase chain reaction was performed to determine the mRNA expression levels of multidrug resistance gene 1 (MDR1) in the two cell lines. Although the Saos-2/MTX4.4 cells were more resistant to the chemotherapeutic agents than the Saos-2 cells, no significant difference was identified between the relative mRNA expression levels of MDR1 in the Saos-2/MTX4.4 and Saos-2 cells $(0.4350 \pm 0.0354$ vs. $0.3886 \pm 0.0456 ; \mathrm{P}>0.05)$.
\end{abstract}

\section{Introduction}

Osteosarcoma is a common type of bone cancer that predominantly occurs during adolescence, and is clinically characterized by local infiltration and early, distant,

Correspondence to: Dr Guojun Li, Department of Orthopedics, Henan University Huaihe Hospital, 8 Baogong Lake North Road, Kaifeng, Henan 475001, P.R. China

E-mail: guojunlicn@126.com

Key words: osteosarcoma cell lines, drug resistance, methotrexate, overcoming resistance hematogenous metastasis (1-3). Although the prognosis of osteosarcoma patients has significantly improved since the implementation of a comprehensive treatment strategy using surgery and adjuvant chemotherapy (4-7), the prognosis remains poor for a number of patients due to the development of acquired resistance. Intrinsic resistance is a phenomenon that occurs prior to chemotherapy and is not associated with the administration of chemotherapeutic agents, whereas acquired resistance is induced by chemotherapeutic agents $(8,9)$. In clinical practice, adjuvant chemotherapy for osteosarcoma generally includes the administration of methotrexate (MTX), cisplatin [cis-diamminedichloroplatinum II [DDP)], ifosfamide (IFO), doxorubicin, pirarubicin or a combination of these agents. High-dose MTX is considered to be the key agent in determining the chemotherapeutic outcome of osteosarcoma patients (10); however, multidrug resistance often develops in the late stage of treatment. In the present study, shock treatment and a gradually increasing dose of MTX were used to investigate acquired resistance in the MTX-resistant osteosarcoma cell line, Saos-2/MTX4.4. Our previous study demonstrated that MTX induces resistance in MTX-resistant cell lines (11). This resistance may be associated with the downregulation of folate carrier gene expression levels, as well as the reduced cellular influx of MTX, reducing the ability of MTX to competitively inhibit tumor cell DNA synthesis (12-15). In the present study, the multidrug resistance of the Saos-2/MTX4.4 cell line was investigated. Furthermore, the association between multidrug resistance and multidrug resistance gene 1 (MDR1) overexpression was determined in the presence of substrates of P-glycoprotein (Pgp), a product of the MDR1 gene. The aim of the present study was to investigate the efficacy of verapamil (VER) in preventing Pgp pumping MTX out of the cell, in order to overcome MTX resistance in osteosarcoma treatment.

\section{Materials and methods}

Cell culture and MTT assay. Human osteosarcoma Saos-2 cells (Shanghai Institutes for Biological Sciences, Chinese Academy of Sciences, Shanghai, China) were exposed to shock therapy using gradually increasing concentrations of MTX (1.1, 2.2 and $4.4 \mu \mathrm{M}$; Shanghai New Hualian Pharmaceutical Co., Ltd., Shanghai, China) to create an MTX-resistant cell line. The Saos-2 parent cells were cultured in RPMI-1640 
medium (Invitrogen Life Technologies, Carlsbad, CA, USA) with $10 \%$ fetal bovine serum (HyClone, Logan, UT, USA) ) and $0.2 \%$ penicillin/streptomycin (Sigma-Aldrich, St. Louis, $\mathrm{MO}, \mathrm{USA})$, at $37^{\circ} \mathrm{C}$ and $5 \% \mathrm{CO}_{2}$. When the cells had reached $60-70 \%$ confluence in the logarithmic growth phase, $4.4 \mu \mathrm{M}$ MTX was added. After $24 \mathrm{~h}$, the cells were washed twice with $1 \mathrm{X}$ phosphate-buffered saline (PBS) at $37^{\circ} \mathrm{C}$, and an agent-free medium was added to the cells. Once the cells had grown to $60-70 \%$ confluence in a logarithmic phase, the process was repeated three times at each MTX concentration. Following seven months of resistance-induction, the MTX-resistant cell line, termed Saos-2/MTX4.4, was established and compared with the primary Saos-2 cells.

An MTT assay (Sigma-Aldrich) was used to determine the sensitivity of the Saos-2 and Saos-2/MTX4.4 cells to MTX, IFO (Jiangsu Henrui Medicine Co., Ltd., Jiangsu, China), DDP (Haosen Pharmaceutical Co., Ltd., Jiangsu, China), Adriamycin (ADM; Zhejiang Haizheng Pharmaceuticals, Taizhou, China), epirubicin (EPI; Pfizer, Inc., Madison, NJ, USA) and theprubicin (THP; Shenzhen Wanle Pharmaceutical Co., Ltd., Shenzhen, China). Logarithmic growth phase cells were suspended in RPMI-1640 medium, seeded in a 96-well plate at $200 \mu \mathrm{l} /$ well $\left(1 \times 10^{4}\right.$ cells) and cultured for $24 \mathrm{~h}$. Based on the peak plasma concentrations of the clinical agents, seven concentration gradients $(1000,100,10,1,0.1$, 0.01 and 0.001 plasma protein concentration) of MTX, DDP, IFO, EPI and THP were added. Untreated cells were used as the control. After $24 \mathrm{~h}$ of incubation, $20 \mu \mathrm{l}$ of 5\% MTT was added to each well, and after another $4 \mathrm{~h}$ of incubation, the culture supernatant was removed, $150 \mu 1$ dimethylsulfoxide was added to each well and the cell mixture was agitated for $10 \mathrm{~min}$ at room temperature. A Wellscan MK3 microplate reader (Labsystems Dragon, Helsinki, Finland) measured the light absorption of the cells at a wavelength of $490 \mathrm{~nm}$. The inhibitory rate of the cells was determined using the following formula: Inhibitory rate $=(1$ - mean absorption value of resistance group / mean absorption value of control group) $\mathrm{x} 100$. The median inhibitory concentration $\left(\mathrm{IC}_{50}\right)$ was identified and the resistance index $(\mathrm{RI})$ of the two cell lines was determined using the following formula: $\mathrm{RI}=\mathrm{IC}_{50}\left(\right.$ Saos-2/MTX4.4) $/ \mathrm{IC}_{50}($ Saos-2) .

Rhodamine 123 (R123) efflux. The Pgp activity of the cell lines was determined by evaluating R123 efflux. R123 is a Pgp-specific fluorescent substrate and its intracellular accumulation is associated with the efficiency of Pgp activity. The changing rate of R123 efflux was determined using the following equation: Rate of efflux = (fluorescence intensity of experimental group - fluorescence intensity of control group) / fluorescence intensity of control group x 100. Equal quantities of Saos-2 and Saos-2/MTX4.4 cells were seeded on a 96 -well plate (density, $\sim 1 \times 10^{5}$ cells/well) and cultured in RPMI-1640 medium for $24 \mathrm{~h}$. The cells were divided into four groups: Primary cells (Saos-2; group A), MTX-resistant cells (Saos-2/MTX4.4; group B), primary cells treated with VER (group C) and MTX-resistant cells treated with VER (group D). VER was added to the wells containing group C and D cells at a final concentration of $4.5 \mu \mathrm{M} 1 \mathrm{~h}$ prior to the addition of R123. R123 was added into all wells at a final concentration of $0.15 \mu \mathrm{g} / \mathrm{ml}$. Each group was replicated in six wells and incubated in an atmosphere of $5 \% \mathrm{CO}_{2}$ and $100 \%$ humidity. Three wells from groups C and D were harvested 30 min after incubation with VER and R123, and the other three wells were harvested 60 min after incubation. Subsequent to being harvested, these cells were rinsed twice with PBS, resuspended in RPMI-1640 medium and observed using fluorescence microscopy (IX17; Olympus Corporation, Tokyo, Japan). Following a further $4 \mathrm{~h}$ of incubation, all the cells were harvested, washed twice with D-Hank's solution (Shanghai Jiaotong University Laboratory, Shanghai, China) and digested at $4^{\circ} \mathrm{C}$ overnight in a $50 \%$ ethanol solution containing $0.3 \mathrm{~mol} / 1 \mathrm{HCl}$. The fluorescence intensity was measured using a multifunctional microplate reader (Wellscan MK3) at an excitation wavelength of $485 \mathrm{~nm}$ and an emission wavelength of $538 \mathrm{~nm}$.

Semiquantitative analysis of MDR1 mRNA expression. Total RNA was extracted from the cells using TRIzol reagent (Invitrogen Life Technologies) and was subjected to reverse transcription-quantitative polymerase chain reaction (RT-qPCR) using a PrimeScript RT reagent kit (Takara Bio, Inc., Shiga, Japan), according to the manufacturer's instructions. Gene-specific primer pairs were designed based on the human MDR1 and $\beta$-actin complementary DNA sequences (GenBank Assembly ID: GCA_000161855.1) from Genbank (www.ncbi.nlm.nih.gov/genbank) and were synthesized by Sangon Biotech Co., Ltd (Shanghai, China). The primer sequences were as follows: Forward, 5'-GTT GCT GCT TAC ATT CAG GTT TC-3' and 5'-ACC AGC CTA TCT CCT GTC GC-3' for MDR1; and forward, 5'-AAC TGG GAC GAC ATG GAG AAA ATC-3' and reverse, 5'-AGG AAG GAA GGC TGG AAG AGT GC-3' for $\beta$-actin. PCR reactions were performed using GeneAmp PCR System 9700 (Applied Biosystems Life Technologies, Foster City, CA, USA), with pre-denaturation at $95^{\circ} \mathrm{C}$ for $5 \mathrm{~min}$, followed by 35 cycles at $94^{\circ} \mathrm{C}$ for $30 \mathrm{sec}, 64^{\circ} \mathrm{C}$ for $30 \mathrm{sec}$ and $72^{\circ} \mathrm{C}$ for $60 \mathrm{sec}$.

Statistical analysis. All experiments were conducted in triplicate. Data were analyzed using SPSS software (version 13.0; SPSS, Inc., Chicago, IL, USA), and are expressed as the mean \pm standard deviation. Comparisons between two groups were performed using one-way analysis of variance, and $\mathrm{P}<0.05$ was considered to indicate a statistically significant difference.

\section{Results}

MTT assay. The $\mathrm{IC}_{50}$ of the Saos-2/MTX4.4 cells to MTX was 12.73 times higher than that of the Saos-2 cells, giving an RI of 12.73, indicating that Saos-2/MTX4.4 cells exhibit moderate resistance to MTX. The Saos-2/MTX4.4 cells demonstrated lower resistance to IFO, ADM, EPI and THP; however, the Saos-2/MTX4.4 cells exhibited no evident cross-resistance to DDP (Table I).

R123 efflux in the Saos-2/MTX4.4 and Saos-2 cells. Fluorescence microscopy demonstrated that 30 or $60 \mathrm{~min}$ post-incubation, the cells in groups $\mathrm{A}$ and $\mathrm{B}$ exhibited full shapes or multiple pseudopodia. In addition, 30 or $60 \mathrm{~min}$ post-incubation, the cells in groups $\mathrm{C}$ and $\mathrm{D}$ also exhibited 

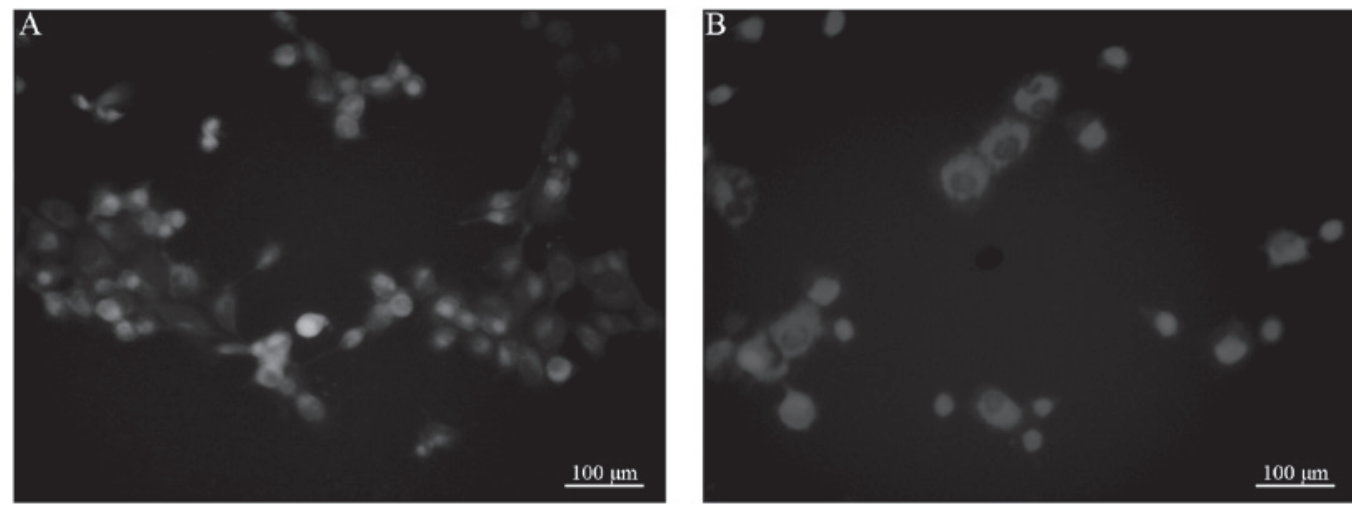

Figure 1. Fluorescence intensity of group A cells: Saos-2 cells at (A) 30 and (B) 60 min after rhodamine 123 administration.
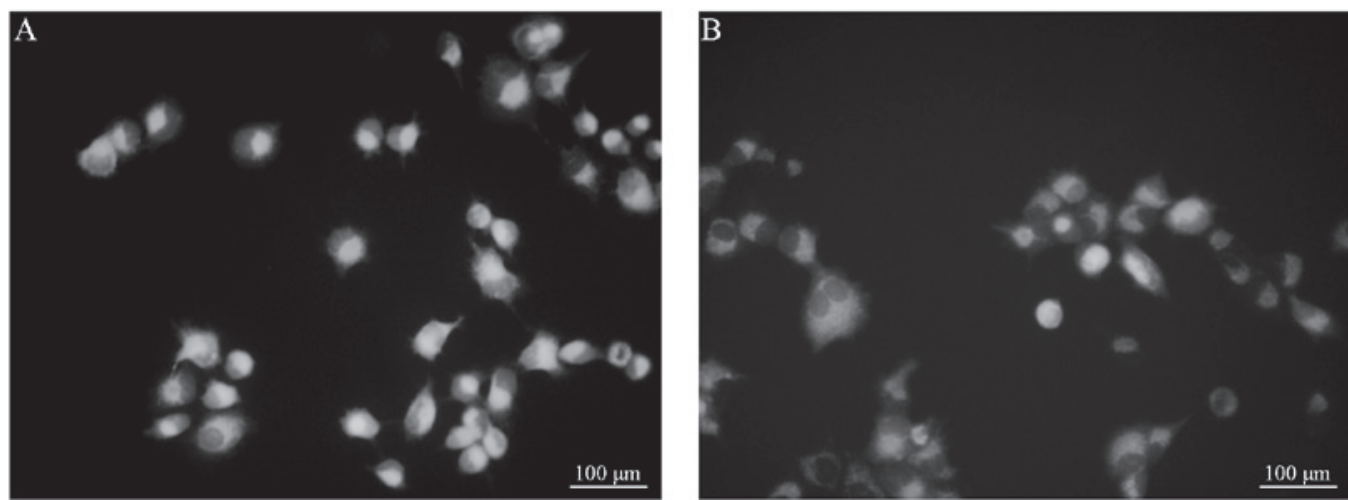

Figure 2. Fluorescence intensity of group B cells: Saos-2/MTX4.4 cells at (A) 30 and (B) 60 min after rhodamine 123 administration.
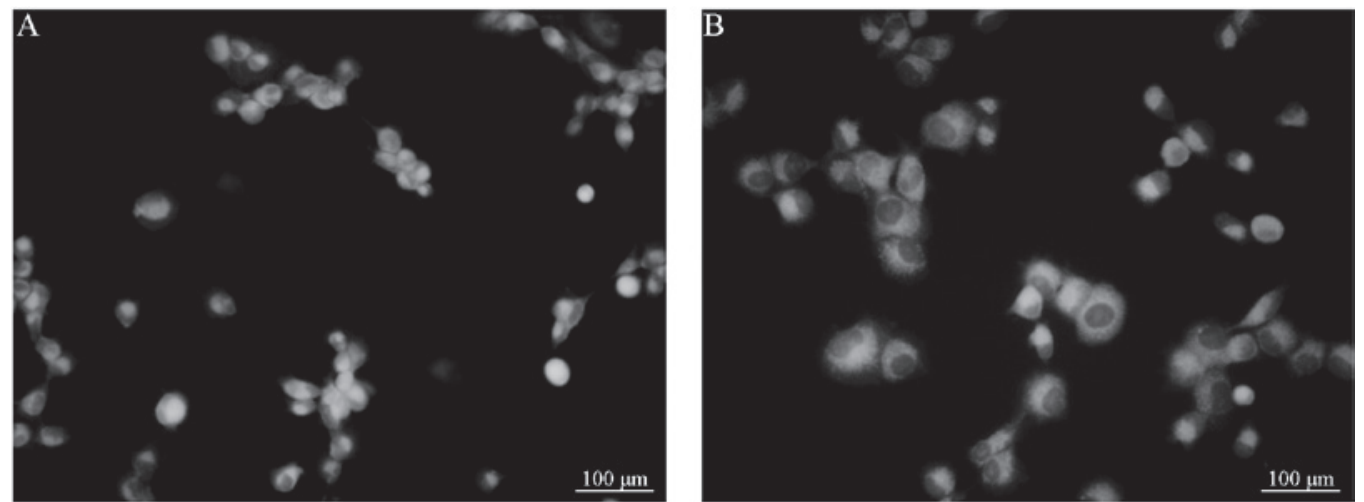

Figure 3. Fluorescence intensity of group C cells: Saos-2 cells at (A) 30 and (B) 60 min after rhodamine 123 and verapamil administration.
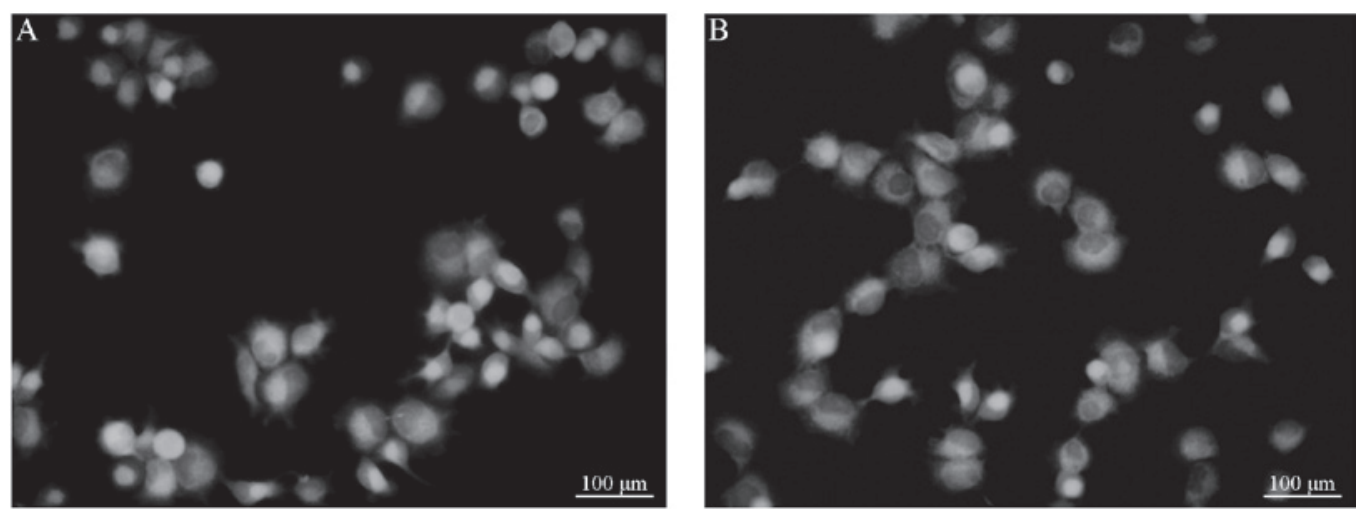

Figure 4. Fluorescence intensity of group D cells: Saos-2/MTX4.4 cells at (A) 30 and (B) 60 min after rhodamine 123 and verapamil administration. 
Table I. Resistance of Saos-2 and Saos-2/MTX4.4 cells to various chemotherapeutic agents $\left[\mathrm{IC}_{50}(\mu\right.$ mol/l) mean \pm standard deviation].

\begin{tabular}{lrrr}
\hline Chemotherapeutic agent & \multicolumn{1}{c}{ Saos-2 } & Saos-2/MTX4.4 & RI \\
\hline MTX & $25.78 \pm 0.29$ & $328.24 \pm 0.29$ & 12.73 \\
IFO & $583.23 \pm 0.14$ & $2346.52 \pm 0.37$ & 4.02 \\
DDP & $127.67 \pm 0.21$ & $156.56 \pm 0.87$ & 1.23 \\
ADM & $8.80 \pm 0.45$ & $34.67 \pm 0.23$ & 3.94 \\
EPI & $10.68 \pm 0.35$ & $43.67 \pm 0.46$ & 4.09 \\
THP & $12.29 \pm 0.72$ & $38.72 \pm 0.25$ & 3.15 \\
\hline
\end{tabular}

MTX, methotrexate; RI, resistance index; IFO, ifosfamide; DDP, cisplatin; ADM, Adriamycin; EPI, epirubicin; THP, theprubicin.

Table II. Rhodamine 123 fluorescence intensity in four groups at various time-points [(arb. unit) mean \pm standard deviation].

\begin{tabular}{lcc}
\hline \multirow{2}{*}{ Group } & \multicolumn{2}{c}{ Incubation period, $\min$} \\
\cline { 2 - 3 } A & 30 & 60 \\
B & $4.35 \pm 0.20$ & $3.25 \pm 0.12$ \\
C & $4.89 \pm 0.32$ & $3.20 \pm 0.21$ \\
D & $6.58 \pm 0.45$ & $5.20 \pm 0.23$ \\
\hline
\end{tabular}

Group A, primary cells (Saos-2); Group B, methotrexate-resistant cells (Saos-2/MTX4.4); Group C, primary cells with verapamil; Group D, methotrexate-resistant cells with verapamil. ${ }^{a} \mathrm{P}<0.05$ vs. group $\mathrm{B}$.

full shapes or multiple pseudopodia. However, no significant differences in cell morphology were observed between the groups. Furthermore, the intracellular fluorescence intensity of the cells was apparent, and no significant differences were identified between groups A and B (Figs. 1 and 2). Following treatment with VER, the fluorescence intensity of the group $\mathrm{C}$ cells demonstrated no significant difference from that of the group D cells (Figs. 3 and 4). However, the cells in groups $\mathrm{C}$ and $\mathrm{D}$ demonstrated a marked difference in fluorescence intensity compared with cells from groups A and group B, respectively. Considering that the cells were digested and detected using a multifunctional microplate reader, the results are consistent with the observations obtained from fluorescence microscopy. No significant difference was identified between the R123 fluorescence intensity of the primary and resistant cells. However, significant differences were observed prior to and following the addition of VER in the primary and resistant cell groups $(\mathrm{P}<0.05$; Table II).

MDR1 mRNA expression in Saos-2/MTX4.4 cells. The MDR1 mRNA expression level is expressed as the ratio of the optical density of MDR1 RT-qPCR products to the optical density of the $\beta$-actin RT-qPCR products. The optical density of the $\beta$-actin band in each lane was set to one and the relative MDR1 mRNA expression was calculated using gel-imaging system analysis software (Quantity One v4.6; Bio-Rad
Laboratories, Hercules, CA, USA). The MDR1 mRNA relative expression levels in the Saos-2/MTX4.4 and Saos-2 cells were $0.4350 \pm 0.0354$ and $0.3886 \pm 0.0456$, respectively. A t-test identified no significant difference between the MDR1 mRNA expression levels in the Saos-2 and Saos-2/MTX4.4 cells.

\section{Discussion}

The concept of the multidrug resistance of tumors was initially proposed in 1970 (16) and stated that tumor cells exhibit a cross-resistance to a variety of chemotherapeutic agents with different structures and functions. Various basic and clinical studies have indicated that, in the majority of cancers, multidrug resistance is associated with the expression of the MDR1 gene. The protein product of MDR1 is $\mathrm{P}-170$, a membrane glycoprotein that functions as an energy-dependent drug pump. P-170 actively exports various anticancer drugs and hydrophobic compounds to reduce the intracellular drug concentration, ultimately resulting in drug resistance (17-24). Numerous studies (17-24) have indicated that doxorubicin-resistant cell lines generally exhibit increased MDR1 gene expression. In the present study, the induced MTX-resistant cell line also showed multidrug resistance. Schwartz et al (19) used an immunohistochemical assay to investigate Pgp expression in biopsy specimens from 685 osteosarcoma patients prior to treatment with chemotherapy, and identified that Pgp expression was not correlated with patient prognosis. However, Baldini et al (25) supported the finding that the Pgp expression level predicts the clinical effects of doxorubicin-based chemotherapy. Thus, Pgp cannot be used as a single predictor of doxorubicin-resistance in the treatment of osteosarcoma. The results of the present study are consistent with these findings. Although the MTX-resistant cell line exhibited multidrug resistance, no significant difference was identified in the expression of the MDR1 gene between the primary and MTX-resistant cells. Furthermore, similar results were identified for R123 efflux; no significant difference was identified in the rate of R123 efflux between the primary and MTX-resistant cells. Thus, MDR1 gene expression may not be the primary cause of multidrug resistance and the efflux of therapeutic agents via the Pgp pathway may not be the primary route of multidrug resistance. 
Previously, VER has been reported to reverse multidrug resistance $(26,27)$. Consistent with this, the present study demonstrated that VER significantly increased the efflux of R123, indicating that VER increases the quantity of soluble intercellular agents by inhibiting the function of Pgp, thus increasing the efficiency of chemotherapeutic agents. However, patients are unable to tolerate treatment with VER due to its toxic cardiovascular side-effects, thus limiting the application of VER in clinical practice (28-31). In conclusion, further investigation into the underlying mechanism of VER activity may provide alternative means for the development of novel therapeutics.

\section{References}

1. Bielack SS, Kempf-Bielack B, Delling G, et al: Prognostic factors in high-grade osteosarcoma of the extremities or trunk: an analysis of 1,702 patients treated on neoadjuvant cooperative osteosarcoma study group protocols. J Clin Oncol 20: 776-790, 2002.

2. Bacci G, Longhi A, Versari M, Mercuri M, Briccoli A and Picci P: Prognostic factors for osteosarcoma of the extremity treated with neoadjuvant chemotherapy: 15-year experience in 789 patients treated at a single institution. Cancer 106: 1154-1161, 2006.

3. Ottaviani G and Jaffe N: The epidemiology of osteosarcoma Cancer Treat Res 152: 3-13, 2009.

4. Ferrari S, Smeland S, Mercuri M, et al: Neoadjuvant chemotherapy with high-dose Ifosfamide, high-dose methotrexate, cisplatin, and doxorubicin for patients with localized osteosarcoma of the extremity: a joint study by the Italian and Scandinavian Sarcoma Groups. J Clin Oncol 23: 8845-8852, 2005.

5. Lewis IJ, Nooij MA, Whelan J, et al; MRC BO06 and EORTC 80931 collaborators; European Osteosarcoma Intergroup: Improvement in histologic response but not survival in osteosarcoma patients treated with intensified chemotherapy: a randomized phase III trial of the European Osteosarcoma Intergroup. J Natl Cancer Inst 99: 112-128, 2007.

6. Meyers PA, Schwartz CL, Krailo MD, et al; Children's Oncology Group: Osteosarcoma: the addition of muramyl tripeptide to chemotherapy improves overall survival - a report from the Children's Oncology Group. J Clin Oncol 26: 633-638, 2008.

7. Anninga JK, Gelderblom H, Fiocco M, et al: Chemotherapeutic adjuvant treatment for osteosarcoma: where do we stand? Eur J Canc 47: 2431-2445, 2011.

8. Le Deley MC, Guinebretière JM, Gentet JC, et al; Société Française d'Oncologie Péediatrique (SFOP): SFOP OS94: a randomised trial comparing preoperative high-dose methotrexate plus doxorubicin to high-dose methotrexate plus etoposide and ifosfamide in osteosarcoma patients. Eur J Cancer 43: 752-761, 2007.

9. Patiño-Garcia A, Zalacaín M, Marrodán L, San-Julián M and Sierrasesúmaga L: Methotrexate in pediatric osteosarcoma: response and toxicity in relation to genetic polymorphisms and dihydrofolate reductase and reduced folate carrier 1 expression. J Pediatr 154: 688-693, 2009.

10. Delepine N, Delepine G, Jasmin C, Desbois JC, Cornille H and Mathé G: Importance of age and methotrexate dosage: prognosis in children and young adults with high-grade osteosarcomas. Biomed Pharmacother 42: 257-262, 1988.

11. Wang JJ and Li GJ: Relationship between RFC gene expression and intracellular drug concentration in methotrexate-resistant osteosarcoma cells. Genet Mol Res 13: 5313-5321, 2014.

12. Laverdière $C$, Chiasson S, Costea I, Moghrabi A and Krajinovic M Polymorphism G80A in the reduced folate carrier gene and its relationship to methotrexate plasma levels and outcome of childhood acute lymphoblastic leukemia. Blood 100: 3832-3834, 2002.
13. Hattinger CM, Reverter-Branchat G, Remondini D, et al: Genomic imbalances associated with methotrexate resistance in human osteosarcoma cell lines detected by comparative genomic hybridization-based techniques. Eur J Cell Biol 82: 483-493, 2003.

14. Kaufman Y, Drori S, Cole PD, et al: Reduced folate carrier mutations are not the mechanism underlying methotrexate resistance in childhood acute lymphoblastic leukemia. Cancer 100: 773-782, 2004.

15. Serra M, Reverter-Branchat G, Maurici D, et al: Analysis of dihydrofolate reductase and reduced folate carrier gene status in relation to methotrexate resistance in osteosarcoma cells. Ann Oncol 15: 151-160, 2004.

16. Biedler JL and Riehm H: Cellular resistance to actinomycin D in Chinese hamster cells in vitro: Cross-resistance, radioautographic and cytogenetic studies. Cancer Res 30: 1174-1184, 1970.

17. Stein U, Walther W and Wunderlich V: Point mutations in the mdrl1 promoter of human osteosarcomas are associated with in vitro responsiveness to multidrug resistance relevant drugs. Eur J Cancer 30A: 1541-1545, 1994.

18. Fan K, Fan D, Cheng LF and Li C: Expression of multidrug resistance-related markers in gastric cancer. Anticancer Res 20: 4809-4814, 2000.

19. Schwartz CL, Gorlick R, Teot L, et al; Children's Oncology Group: Multiple drug resistance in osteogenic sarcoma: INT0133 from the Children's Oncology Group. J Clin Oncol 25: 2057-2062, 2007.

20. Benderra Z, Faussat AM, Sayada L, et al: Breast cancer resistance protein and $\mathrm{P}$-glycoprotein in 149 adult acute myeloid leukemias. Clin Cancer Res 10: 7896-7902, 2004.

21. Kim DH, Lee NY, Sung WJ, et al: Multidrug resistance as a potential prognostic indicator in acute myeloid leukemia with normal karyotypes. Acta Haematol 114: 78-83, 2005.

22. Marsh S, Paul J, King CR, Gifford G, McLeod HL and Brown R: Pharmacogenetic assessment of toxicity and outcome after platinum plus taxane chemotherapy in ovarian cancer: the Scottish Randomised Trial in Ovarian Cancer. J Clin Oncol 25: 4528-4535, 2007.

23. Müller PJ, Dally H, Klappenecker CN, et al: Polymorphisms in $\mathrm{ABCG} 2, \mathrm{ABCC} 3$ and $\mathrm{CNT} 1$ genes and their possible impact on chemotherapy outcome of lung cancer patients. Int J Cancer 124: 1669-1674, 2009.

24. Sun N, Sun X, Chen B, et al: MRP2 and GSTP1 polymorphisms and chemotherapy response in advanced non-small cell lung cancer. Cancer Chemother Pharmacol 65: 437-446, 2010.

25. Baldini N, Scotlandi K, Serra M, et al: P-glycoprotein expression in osteosarcoma: a basis for risk-adapted adjuvant chemotherapy. J Orthop Res 17: 629-632, 1999.

26. Smith MA, Merry S, Smith JG and Kaye SB: Clinically relevant concentrations of verapamil do not enhance the sensitivity of human bone marrow CFU-GM to adriamycin and VP16. Br J Cancer 57: 576-578, 1988.

27. Shudo N, Mizoguchi T, Kiyosue T, Arita M, Yoshimura A, Seto K, Sakoda R and Akiyama S: Two pyridine analogues with more effective ability to reverse multidrug resistance and with lower calcium channel blocking activity than their dihydropyridine counterparts. Cancer Res 50: 3055-3061, 1990.

28. Mahmood M, Mustafa T, Xu Y, Nima Z, Kannarpady G, Bourdo S, Casciano D and Biris AS: Calcium-channel blocking and nanoparticles-based drug delivery for treatment of drug-resistant human cancers. Ther Deliv 5: 763-780, 2014.

29. Othman RT, Kimishi I, Bradshaw TD, Storer LC, Korshunov A, Pfister SM, Grundy RG, Kerr ID and Coyle B: Overcoming multiple drug resistance mechanisms in medulloblastoma. Acta Neuropathol Commun 2: 57, 2014.

30. Zu Y, Yang Z, Tang S, Han Y and Ma J: Effects of P-glycoprotein and its inhibitors on apoptosis in K562 cells. Molecules 19: 13061-13075, 2014.

31. Kim SS, Seong S and Kim SY: Synergistic effect of ginsenoside $\mathrm{Rg} 3$ with verapamil on the modulation of multidrug resistance in human acute myeloid leukemia cells. Oncol Lett 7: 12651269,2014 